Diversity of Research in Health Journal / Revue de la Diversité de la Recherche en Santé

Vol 4, January/ Janvier 2021 - ISSN: 2561 -1666 DOI : 10.28984/drhj.v4i1.337

\title{
Can Intentional Distractions Affect Endurance Performance Positively?
}

\section{R. T. Couture}

DRHJ/RDRS 2021, 4, pp.141-155

\author{
Roger T. Couture, Ph.D. \\ Full Professor, rcouture@laurentian.ca \\ School of Kinesiology and Health Sciences, Faculty of Health \\ Laurentian University, Sudbury (ON), Canada.
}

\begin{abstract}
Distractions are often associated with negative outcomes however; distractions can also benefit people. Using the hypothesis of internal-external distractions in the competition for cue, this study examined the effects of an active (controlled) and passive (uncontrolled) distraction on three endurance tasks. Participants ( $\mathrm{N}=42$ ), aged 20 to 23 years were assigned to three groups. Tasks and conditions were counterbalanced across groups to minimize the residual effects of fatigue, learning an intervention and other confounding variables. Performance time, heart rate, ratings of perceived exertion and perceived fatigue were measured. Results showed that active distraction significantly improved performance and lowered Rate of Perceived Exertion in one task. As expected, the active distraction group was the least accurate for estimating time spent. Passive distraction caused minimal performance change. More investigation is needed to understand why an active distraction only affected one trial. Future studies should delve into means for better understanding the hypothesis of competition for cue.
\end{abstract}

Keywords: Performance, Thinking Strategies, Associative, Dissociative, Distractions

\section{Résumé}

Les distractions sont souvent associées à des résultats négatifs, cependant, les distractions peuvent aussi être bénéfiques. En utilisant l'hypothèse de la compétition de l'attention 'interne-externe', cette étude a examiné les effets d'une distraction active (contrôlée) et passive (non contrôlée) sur trois tâches d'endurance différentes. Les participants $(\mathrm{N}=42)$, âgés de 20 à 23 ans, furent distribués au hasard en trois groupes et trois épreuves d'endurance furent effectuées. Le temps de performance, la fréquence cardiaque, les évaluations de l'effort perçu et la fatigue perçue ont été mesurés. Les résultats d'une épreuve ont montré que la distraction active a amélioré les performances significativement seulement dans une épreuve tout en diminuant la perception de l'effort. La distraction active était le moins précis pour estimer le temps passé lors d'un exercice. Une étude future pourrait examiner pourquoi seulement une de trois épreuves a montré ces changements significatifs selon l'hypothèse de la compétition de l'attention.

Mots-clés : Performance, Stratégies de pensée, Associatif, Dissociatif, Distractions 
Diversity of Research in Health Journal / Revue de la Diversité de la Recherche en Santé

Vol 4, January/ Janvier 2020 - ISSN: 2561 -1666 DOI : 10.28984/drhj.v4i1.337

\section{Introduction}

Some distractions can be costly or even deadly in our society (i.e. poor work performance, poor grades, distracted driving, etc.). However, people around the world have long used intentional distractions (i.e. listen to music or sing while working or walking, think of unrelated thoughts while driving, etc.). Common outcomes of good distractions have included feelings of mental relaxation (Waugh, Shing, \& Furr, 2020), pain control (McCaul \& Malott, 1984), better mood states (Privitera, Antonelli, \& Szal, 2014), perception that time passes by more quickly. Certain distractions have resulted in better performance in some athletic settings, work settings and in everyday life situations. Some researchers have explained this phenomenon using a dichotomy of thoughts.

Pennebaker (1982) hypothesises that people have potential sources of information originating from inside (thoughts) and outside (environment) themselves. He explains that internal arousal is an on-going process of fluctuating intensities that normally maintains a homeostatic relationship with external stimulation. Consequently, a competition of cues occurs when either internal or external stimulation outweighs the other for additional attention. For example, a student who is nearing the end of the semester with many expectations (i.e., studying, report submissions, exams, grocery shopping, paying bills, etc.) is flooded by external stimuli during the stressful period. After the stressful events, the student may become aware that a toothache, cold or headache has been lingering (external cues). However, if any of the before mentioned ailments increased in pain, the cues would have attracted more attention. Symptoms measure internal stimulation while external stimuli are measured through a variety of factors (performance, vigilance, dexterity, etc.). This competition for cues varies depending on quantity and quality. The winning type of stimulation thus becomes the deciding factor for a bodily response. Some researchers have thought that people have a limited mental channel capacity of information processing. Stevinson and Biddle (1998) attempted to add clarity in Pennebaker's conceptual structure and in other researchers' studies by categorizing thoughts during exercise as being inward monitoring (e.g. fatigue), outward monitoring (e.g. strategy), inward distraction (e.g. daydreaming) or outward distraction (e.g. scenery).

Depending on the person's level of mental tolerance, too much or too little information leads to fatigue (Finkelman, 1994) and to poor performance. Interestingly, some studies have shown that a divergent attentional motivation could depend more on the caliber of athletes (elite vs novice) where the experienced athletes choose to use a variety of strategies at different times for different purposes while the less experienced or lower performing participants are more inclined to choosing from a smaller range of options. For example, Baker, Côté, and Deakin (2005) found that high-level triathletes tended to focus on more performance-related thinking strategies (e.g. pacing, mental race planning from start to finish, strategizing on passing competitors). Triathletes in the middle of the pack and especially those at the end, tended to mentally focus more on taskirrelevant thoughts and looking forward to having completed the race. Boya et al. (2017) made similar findings when they looked at elite cyclists, as they fixated mostly on being as efficient as possible during a simulated $16.1 \mathrm{~km}$ time-trial. In comparison, low-level cyclists thought more 
Diversity of Research in Health Journal / Revue de la Diversité de la Recherche en Santé Vol 4, January/ Janvier 2020 - ISSN: 2561 -1666 DOI : 10.28984/drhj.v4i1.337

about the distance they had to travel in terms of completing the task, the discomfort or pain being felt, the next hill, etc. and other unrelated distractions (i.e. things to do after the race, mental shopping list during the race, count the number of bikes in the race, etc.).

Endurance athletes like marathon runners, cross-country skiers, long-distance cyclists and distance swimmers use cognitive thinking strategies for racing or training purposes (Brick, Campbell, Sheehan, Fitzpatrick, and MacIntyre, 2020; Couture et al, 2000). Depending on people's level of competitive proficiency, studies have shown that some individuals direct their attention away from specific tasks or their importance (Couture, Jerome \& Tihanyi, 1999; Weinberg \& Gould, 1995) while others have focused intensely on the activity (Boya et al., 2017), provided that athletes perceive having control over the distraction (Pensgaard, 1998).

Generally, elite athletes perform well because of their physical prowess, technical abilities and mental fortitude. Many studies have shown that this caliber of athletes tends to use mostly associative cognitions (intensive focusing on the current race strategy along with constant monitoring of their body's functioning), resulting in positive outcomes in terms of performance (Brick, Campbell, Sheehan, Fitzpatrick, and MacIntyre, 2020). With less competitive recreational athletes, studies on attentional focus have shown positive results in reducing levels of boredom, fatigue while improving performances in some athletic endurance sports with elite and non-elite athletes (Chen \& Singer, 1992; Couture, Tihanyi \& St-Aubin, 1998; Masters, 1992; Padgett \& Hill, 1989, Rejeski \& Kenny, 1987).

Distractions can be active or passive as well as external or internal. Active distractions imply that the subject makes a conscious effort to focus on something that is external and unrelated to the endurance task (e.g., counting the number of cars, maintaining a conversation with another participant or internal and unrelated to the task (e.g., reading, calculating or solving concrete problems during an exercise). Passive distractions imply that an individual chooses to be influenced effortlessly by external stimuli (i.e. background noise or music, a relaxing environment with few changing or new stimuli or internal stimuli (i.e. daydreaming, unprovoked thoughts or music). Consequently, competition of cues becomes obvious in taking the person's thoughts away from the present task. These two types of distractions have given mixed results in relation to performance and perceived fatigue.

Pennebaker and Lightner (1980) found that passive distractions could cause both, positive and negative results. In performing two trials; laboratory setting and outdoor setting, they measured the physiological responses of subjects who ran on a treadmill while listening either to distracting street sounds or to their own breathing. The effects of street sounds resulted in lower perceived fatigue levels than the sound of their breathing. It was suspected that listening to one's breathing closely resembled associative thinking or internal focusing instead of dissociative thinking. No physiological or performance changes were observed between groups. In a second trial, recreational runners were randomly assigned to two groups. One group ran on a crosscountry trail (with natural obstacles like roots, rocks, branches) while a second group ran the same distance on a running track (with no obstacles). Though perceived fatigue had not changed drastically, timed performance was fastest with the cross-country runners (active external 
Diversity of Research in Health Journal / Revue de la Diversité de la Recherche en Santé

Vol 4, January/ Janvier 2020 - ISSN: 2561 -1666 DOI : 10.28984/drhj.v4i1.337

distractions) on the trail. In this study, distractions on the trail enhanced performance without affecting perceived fatigue.

Couture, Jerome and Tihanyi (1999) presented the concept of three types of attentional cognitions. Swimmers performed one of three tasks during a 500-meter swim. The external distractions group counted and reported the number of geometric shapes (square, circle, triangle) seen after each 50-meter pool length during the swim. The dissociative (internal distractions) group focused on something non-stressful and unrelated to swimming. The associative group (external breath counting group) physically said "air" when inhaling. Results showed that the associative thinking group swam significantly faster yet had the highest score in terms of perceived fatigue of all groups. Associative strategies are normally related with better performance while dissociative strategies are normally related with less fatigue and sometimes better performance (i.e. Pennebaker and Lightner, 1980). With non-athletes, a similar tendency would be expected however, some studies have shown interesting outcomes. For instance, Martin et al. (1984) found that participants who dissociated from the task of attending a twelve-week aerobic programme had a greater attendance record (76.6\%) than a group instructed to mentally associate by monitoring their bodily sensations (58.7\%). In examining attentional cognition strategies (active external and active internal distractions), Gill and Strom (1985) examined participants' ability to tolerate exercise efforts on a leg extension machine while focusing either on a collage or on a personal thought. The active external distraction group with the collage could endure the leg extension longer than the "personal thought" internal distraction group and control group.

Other studies have shown mixed results with passive distraction like music and background sounds (Boutcher and Trenske, 1990; Fillingim, Roth \& Haley, 1989; Franklin, 1978; Hull \& Potteiger, 1999; Schuker, L., Hagemaan, N., Strauss B. \& Volker, K., 2009). Consequently, it is unclear whether active or passive distractions are most beneficial for people in general when performing an endurance task. The following study examined the effects of active and passive distraction on individuals' performances, perceived exertion and perceived fatigue during three separate sustained endurance tasks.

\section{Method \\ Participants}

Forty-two volunteer university students (27 men and 15 women), aged 20 to 23 years old (mean of 21.6) were randomly assigned to three groups. Following a research ethics approval, participants were provided with an explanation of the procedure, an informed consent form and a Physical Activity Readiness Questionnaire to complete. Each group of fourteen consisted of five females and nine males. A counter-balanced approach helped to minimize fatigue and learning effects. The first and second trials examined leg endurance (right and left, separately) followed by grip strength as the third trial. 
Diversity of Research in Health Journal / Revue de la Diversité de la Recherche en Santé

Vol 4, January/ Janvier 2020 - ISSN: 2561 -1666 DOI : 10.28984/drhj.v4i1.337

\section{Measures and Design}

This study performed randomized counter-balanced block design to perform three different trials. Statistical tools included MANOVAs, ANOVAs and Newman-Keul post-hoc tests. Other studies (Gill and Strom, 1985; Padgett and Hill, 1989; Pennebaker and Lightner, 1980) have performed studies with several trials to look at two distraction types on performance. Physical and perceptual indicators were used during distinct types of trials. In this study, active and passive distractions were performed during three muscular endurance trials. The following measuring instruments were used.

Rating of Perceived Exertion (RPE) This instrument consists in using a 15-point scale and some identifiers and is widely used. Ranging from 6 to 20, every uneven number is paired with a descriptor (e.g., 7 "very very light" and 19 "very very heavy"). This scale has a linear correlation with heart rate (Borg, 1982). The psychometric properties have been deemed acceptable for monitoring, prescribing and regulating exercise levels of intensity (Eston, 2012).

The Perceived Fatigue Questionnaire (PFQ) was used for a similar reason. This questionnaire was created based on the "competition for cues" construct, used to measures changes in perceived mental fatigue. Studies have shown that individuals' focus on attention can be affected by internal sensory cues and external environmental stimuli (Couture, Jerome and Tihanyi, 1999; Pennebaker and Lightner, 1980; Pennebaker, 1982). In line with the competition for cues theory, the PFQ examines ten physiological symptoms related to fatigue are listed and evaluated with a scale from 1 to 100 (dizziness, sore eyes, headache, etc.). Participants mark with a slash how they feel (e.g., $0=$ not at all dizzy to $100=$ the worst feeling of dizziness ever) for each symptom. A total score provides a general symptom index of fatigue. The scalar properties of these symptoms are appropriate and are discussed in Pennebaker and Skelton (1978).

Two other measurements were gathered to verify the level of active distraction and perceived ratings of exertion. Estimation of the task's duration was measured by asking the participant the number of minutes they thought had gone by while performing the exercise. Absolute numbers were used to identify discrepancies that were either higher or lower than the real time. This measurement was used to confirm that distraction was in fact, happening.

As a second measure, heart rate was taken with a heart rate monitor (VANTAGE XL Sport Tester with transmitter and receiver) once at the beginning and once at the end of each study trial.

\section{Procedure}

A randomized block design allowed for the counterbalancing of the three participant groups across the three exercises. The three endurance exercises comprised of (a) right leg extension, (b) left leg extension and (c) dominant grip hold at 40\% max. To reduce the chances of muscle fatigue, different limbs were used with a rest period of five-minutes between tasks. Participants' wristwatch was replaced by a heart rate monitor on the wrist to avoid affecting people's estimates of their endurance time. Three tasks were explained and performed in a sequential order. 
Diversity of Research in Health Journal / Revue de la Diversité de la Recherche en Santé Vol 4, January/ Janvier 2020 - ISSN: 2561 -1666 DOI : 10.28984/drhj.v4i1.337

Right Leg Extension. Using the right bare foot, the participant sat on a $48 \mathrm{~cm}$ high stool. The participant kept the right leg straight for the longest time possible. A Lafayette clock and electrical counter began with the bare heel over a metal plate. The timer stopped when the heel touched the plate. The first two trials employed a timed endurance task using a copper-metal conductance unit with a timer (Lafayette clock/counter, model 54417-A). While sitting on a stool, a rectangular piece of copper metal was taped onto the heel of the participant's bare foot. A metal plate, located on a box, $35 \mathrm{~cm}$ high was the conductance device. An electrical timer started when the participant's heel was above the box and ended when the heel touched the plate. The third trial measuring grip strength, used a hand-held a calibrated dynamometer. The duration of the straight leg hold was taken. Heart rate, RPE and the PFQ were completed before and after the exercise. Participants were then asked to estimate the duration of the endurance task in seconds or minutes. They were not told about their estimates' accuracy.

Left Leg Extension. The same procedure completed for the right leg extension, was performed for the left leg after a five-minute resting period.

Dominant Hand Grip Endurance. While standing, the participant squeezed the grip dynamometer maximally three times using an established protocol (laterally $30 \mathrm{~cm}$ away from the body). An average maximum score was calculated. Using the average of the three squeezes, the participant squeezed and maintained the grip effort at $40 \%$ of their average maximum for as long as possible. RPE and PFQ were completed as they squeezed, followed by their guess at the estimated length of time taken in seconds. Heart rate was recorded before and after the completion of the task.

Interventions. Two distractions were compared to a control group on the three previous trials. Active distraction involved reverse serial counting by three from 600 (i.e., 600, 597, 594, etc) out loud for the researcher to hear. The participant was told that the number of mistakes heard were tabulated. Passive distraction required participants to choose background music. Using headphones, the participant performed the task. Choice of music tempo was given because some research has shown no effect on choice of background music (Szabo, Balogh, Gaspar, Bosze \& Vaczi, 2009). The control group participant was asked to do the established tasks for as long as possible.

The order in which each group performed the task and interventions was as follows: Between each task, participants rested for five-minute break. Five minutes was chosen to avoid doubts of a sufficient rest period and subsequently would not influence the subsequent endurance trials. Studies have shown that rest periods of one to four minutes have commonly been found to be more than adequate for a variety of maximal muscle strength/endurance exercises (Carneiro et al., 2018; Senna, Rodrigues, Sandy, Scudese, Bianco \& Dantas, 2017). The American College of Sports and Medicine recommends rest intervals between two and three minutes between sets of multi-joint exercises (Kravitz, 2009). Garcia-Lopez et al., (2007) considered a one-minute rest to be a short term whereas a long term is four minutes long between resistance training.

Group one began with the right leg extension using active distraction. Five minutes after completing the task, group one performed the left leg extension with passive distraction. Finally, 
Diversity of Research in Health Journal / Revue de la Diversité de la Recherche en Santé

Vol 4, January/ Janvier 2020 - ISSN: 2561 -1666 DOI : 10.28984/drhj.v4i1.337

after the rest period, group one performed the $40 \%$ dominant grip hold with no distraction. Group two began with left leg extension using active distraction, followed by dominant grip hold with passive distraction and finally right leg extension with no distraction. Group three began with dominant grip hold using active distraction, followed by right leg extension with passive distraction and finally left leg extension with no distraction. These changes were designed to eliminate the potential for an "order effect" in each of the tasks. Analyses of studies one, two and three consisted in taking the results of all groups having done the right leg extension (active, passive and no distraction) dominant grip hold (active, passive and no distraction) and the left leg extension (active, passive and no distraction) respectively.

\section{Results}

Participants in each group were similar in group homogeneity with no significant differences in gender and age. In the first trial (Right Leg Extension), data were converted to log scores due to a low homogeneity of variance. A MANOVA revealed no mean statistical differences for performance, heart rate (before and after) and Perceived Fatigue (during and after). However, the active distraction group ( $M=102.8$ seconds) was clearly less accurate than the passive ( $M=52$ seconds) and control groups ( $M=0.35$ seconds) when estimating time during the trial. Using a repeated ANOVA, errors in time estimation had shown an interaction effect $\mathrm{F}(2,39)=$ $6.56 * * \mathrm{p}<.01$ between the experimental groups and the control group. A Newman-Keuls test identified the active distraction to be the cause of the statistical difference as can be seen in Table 1 . 
Diversity of Research in Health Journal / Revue de la Diversité de la Recherche en Santé

Vol 4, January/ Janvier 2020 - ISSN: 2561 -1666 DOI : 10.28984/drhj.v4i1.337

Table 1. Means and standard deviations following the interventions during the right leg extension

Groups

\begin{tabular}{|c|c|c|c|c|c|}
\hline Variables & $\begin{array}{l}\text { Means and } \\
\text { Standard } \\
\text { Deviations }\end{array}$ & $\begin{array}{l}\text { Passive } \\
\text { Distraction }\end{array}$ & $\begin{array}{l}\text { Active } \\
\text { Distraction }\end{array}$ & Control & $\underline{F}$ \\
\hline \multirow{2}{*}{$\begin{array}{l}\text { Performance time (in } \\
\text { seconds) }\end{array}$} & $\underline{\mathrm{M}}$ & 317.71 & 303.5 & 249.64 & \multirow[t]{2}{*}{0.86} \\
\hline & $\overline{\mathrm{SD}}$ & 143.65 & 161.59 & 126.9 & \\
\hline \multirow[t]{2}{*}{$\mathrm{RPE}$} & $\underline{\mathrm{M}}$ & 13.93 & 12.71 & 13.64 & \multirow[t]{2}{*}{1.11} \\
\hline & $\overline{\mathrm{SD}}$ & 2.12 & 2.05 & 2.53 & \\
\hline \multirow[t]{2}{*}{ Heart Rate (before task) } & $\underline{\bar{M}}$ & 73.35 & 71.07 & 71.57 & \multirow[t]{2}{*}{0.26} \\
\hline & $\overline{\mathrm{SD}}$ & 10.00 & 8.19 & 9.85 & \\
\hline \multirow[t]{2}{*}{ Heart Rate (after task) } & $\underline{\bar{M}}$ & 96.71 & 91.07 & 86.71 & \multirow[t]{2}{*}{2.12} \\
\hline & $\overline{\mathrm{SD}}$ & 15.70 & 101.3 & 12.13 & \\
\hline \multirow[t]{2}{*}{ Error in Time Estimate } & $\overline{\mathrm{M}}$ & 52.00 & 102.80 & 0.35 & \multirow[t]{2}{*}{$6.59 * *$} \\
\hline & $\overline{\mathrm{SD}}$ & 47.99 & 87.71 & 82.39 & \\
\hline \multirow[t]{2}{*}{ Perceived Fatigue (during) } & $\underline{\bar{M}}$ & 117.50 & 84.64 & 93.36 & \multirow[t]{2}{*}{0.75} \\
\hline & $\underline{\mathrm{SD}}$ & 79.72 & 62.46 & 74.58 & \\
\hline \multirow[t]{2}{*}{ Perceived Fatigue (after) } & $\underline{\bar{M}}$ & 89.29 & 76.43 & 99.93 & \multirow[t]{2}{*}{0.40} \\
\hline & $\underline{\overline{\mathrm{SD}}}$ & 73.01 & 71.86 & 64.24 & \\
\hline
\end{tabular}

Note. $* \underline{\mathrm{p}}<.05 . * \mathrm{*} \mathrm{p}<.01$

The second part of the study (Left Leg Extension) demonstrated a low homogeneity of variance in scores. Accordingly, endurance performance and time estimate scores were converted to $\log$ scores in order to reduce error sizes. Scores in performance, RPE and time estimation were significantly different between groups, clearly highlighting the active distraction group. The active distraction group's performance mean was highest with 441.85 seconds compared to the passive distraction and control group (288.28 and 249.71 respectively). This group's better endurance scores was clearly shown $(\mathrm{F}(2,39)=3.33 ; \mathrm{p}<.05)$. The same group (active distraction) had the lowest rate of perceived exertion with a score of 12.28 compared to 14.14 and 14.35 (passive distraction and control group respectively). The mean RPE scores were significant $(F(2,39)=3.35$; $\mathrm{p}<.05)$. In terms of time estimate scores, a significant interaction effect was found $\mathrm{F}(2,39)=8.65$; $\mathrm{p}<.05$ where the active distraction group was the least accurate (active distraction= 94 seconds, passive distraction=50.43 seconds, control group=55.10 seconds). As for the other variables, no significant differences were found between groups concerning heart rate (during and after) and perceived fatigue during or near the end of the task, as can be seen in Table 2. 
Diversity of Research in Health Journal / Revue de la Diversité de la Recherche en Santé

Vol 4, January/ Janvier 2020 - ISSN: 2561 -1666 DOI : 10.28984/drhj.v4i1.337

Table 2. Means and standard deviations following the interventions during the left leg Extension

\begin{tabular}{|c|c|c|c|c|c|}
\hline \multirow[b]{2}{*}{ Variables } & \multirow[b]{2}{*}{$\begin{array}{l}\text { Means and } \\
\text { Standard } \\
\text { Deviations }\end{array}$} & \multicolumn{3}{|c|}{ Groups } & \multirow[b]{2}{*}{$\underline{F}$} \\
\hline & & $\begin{array}{l}\text { Passive } \\
\text { Distraction }\end{array}$ & $\begin{array}{l}\text { Active } \\
\text { Distraction }\end{array}$ & Control & \\
\hline Performance Time (in seconds) & $\frac{\mathrm{M}}{\mathrm{SD}}$ & $\begin{array}{l}288.28 \\
129.71\end{array}$ & $\begin{array}{l}441.85 \\
301.42\end{array}$ & $\begin{array}{l}249.71 \\
108.77\end{array}$ & $3.33 *$ \\
\hline RPE & $\frac{\bar{M}}{S D}$ & $\begin{array}{l}14.14 \\
1.83\end{array}$ & $\begin{array}{l}12.28 \\
2.49\end{array}$ & $\begin{array}{l}14.35 \\
2.59\end{array}$ & $3.35^{*}$ \\
\hline Heart Rate (before task) & $\frac{\mathrm{M}}{\mathrm{SD}}$ & $\begin{array}{l}73.35 \\
10.02\end{array}$ & $\begin{array}{l}71.07 \\
8.18\end{array}$ & $\begin{array}{l}71.57 \\
9.85\end{array}$ & 0.23 \\
\hline Heart Rate (after task) & $\frac{\bar{M}}{S D}$ & $\begin{array}{l}91.57 \\
11.84\end{array}$ & $\begin{array}{l}92.07 \\
10.45\end{array}$ & $\begin{array}{l}89.21 \\
10.93\end{array}$ & 0.27 \\
\hline Error in Time Estimate & $\overline{\mathrm{M}}$ & $\begin{array}{l}50.43 \\
61.47\end{array}$ & $\begin{array}{l}94.00 \\
140.50\end{array}$ & $\begin{array}{l}55.10 \\
50.85\end{array}$ & $8.92 * *$ \\
\hline Perceived Fatigue (during) & $\overline{\mathrm{M}}$ & $\begin{array}{l}80.36 \\
46.68\end{array}$ & $\begin{array}{l}109.57 \\
97.96\end{array}$ & $\begin{array}{l}93.57 \\
92.62\end{array}$ & 0.44 \\
\hline Perceived Fatigue (after) & $\frac{\bar{M}}{S D}$ & $\begin{array}{l}85.00 \\
61.11\end{array}$ & $\begin{array}{l}93.36 \\
97.91\end{array}$ & $\begin{array}{l}85.00 \\
96.14\end{array}$ & 0.04 \\
\hline
\end{tabular}

Note. $* \mathrm{p}<.05 . * * \mathrm{p}<.01$

As with the other two tasks and results, the third part of the study (Grip Endurance) data was converted to log scores due to a low homogeneity of variance. No differences were found between groups in performance time, heart rate (during and after), RPE, Perceived Fatigue (during and after) and time estimation as seen in Table 3. 
Diversity of Research in Health Journal / Revue de la Diversité de la Recherche en Santé

Vol 4, January/ Janvier 2020 - ISSN: 2561 -1666 DOI : 10.28984/drhj.v4i1.337

Table 3. Means and standard deviations following interventions during dominant grip strength

\begin{tabular}{|c|c|c|c|c|c|}
\hline \multirow[b]{2}{*}{ Variables } & \multirow[b]{2}{*}{$\begin{array}{l}\text { Means and } \\
\text { Standard } \\
\text { Deviations }\end{array}$} & \multicolumn{3}{|c|}{ Groups } & \multirow[b]{2}{*}{$\underline{\mathrm{F}}$} \\
\hline & & $\begin{array}{l}\text { Passive } \\
\text { Distraction }\end{array}$ & $\begin{array}{l}\text { Active } \\
\text { Distraction }\end{array}$ & Control & \\
\hline \multirow[t]{2}{*}{ Performance Time (in seconds) } & $\underline{\mathrm{M}}$ & 42.21 & 26.14 & 26.50 & 1.93 \\
\hline & $\underline{\mathrm{SD}}$ & 36.81 & 15.13 & 15.63 & \\
\hline \multirow[t]{2}{*}{ RPE } & $\underline{\mathrm{M}}$ & 14.35 & 12.00 & 14.21 & 2.97 \\
\hline & $\underline{\mathrm{SD}}$ & 2.02 & 3.44 & 2.97 & \\
\hline \multirow[t]{2}{*}{ Heart Rate (before task) } & $\underline{\bar{M}}$ & 71.07 & 71.57 & 73.36 & 0.23 \\
\hline & $\underline{\mathrm{SD}}$ & 8.18 & 9.85 & 10.02 & \\
\hline \multirow[t]{2}{*}{ Heart Rate (after task) } & $\underline{\bar{M}}$ & 89.64 & 98.79 & 92.64 & 1.19 \\
\hline & $\underline{\mathrm{SD}}$ & 11.30 & 20.52 & 14.83 & \\
\hline \multirow[t]{2}{*}{ Error in Time Estimate } & $\underline{\mathrm{M}}$ & -3.07 & 6.64 & 6.14 & 0.39 \\
\hline & $\underline{\mathrm{SD}}$ & 32.94 & 7.82 & 17.22 & \\
\hline \multirow[t]{2}{*}{ Perceived Fatigue (during) } & $\underline{\mathrm{M}}$ & 62.93 & 66.43 & 75.71 & 0.21 \\
\hline & $\underline{\mathrm{SD}}$ & 48.86 & 47.33 & 63.33 & \\
\hline \multirow[t]{2}{*}{ Perceived Fatigue (after) } & $\underline{\bar{M}}$ & 69.71 & 49.29 & 65.71 & 0.42 \\
\hline & $\underline{\mathrm{SD}}$ & 48.40 & 49.69 & 82.44 & \\
\hline
\end{tabular}

Note. $* \underline{p}<.05 . * * \underline{p}<.01$.

\section{Discussion}

The results from the three short trials suggest a variety of possibilities. In the first part of the study, minimally higher scores in performance time, heart rate (after the task), rate of perceived exertion and perceived fatigue were noted after the trial. These results do not support Boutcher and Trenske's (1990) study where they found a lower perceived exertion during the passive distraction of music compared with the control condition. Pennebaker's hypothesis of competition for cues suggests that quantity and quality of stimuli were insufficient for a change in greater endurance time in terms of performance. Further, increased heart rate for the passive distraction group did not concur with other internal measuring instruments (i.e., RPE, perceived fatigue questionnaire). Though not significant, the active distraction group scores were lower in RPE and perceived fatigue than the other groups. The end-result expected was a significantly increased tolerance to fatigue as was suggested by Pennebaker (1982; Rejeski \& Kenny, 1987). A larger sample size may have created significant differences.

Interestingly, the highest error in time estimate was from the active distraction strategy. Reverse serial counting was a statistically effective intervention for the group. Other studies have corroborated these findings (Chen \& Singer, 1992; Masters, 1992; Padgett and Hill, 1989). A different set of outcomes were noted in the second trial. 
Diversity of Research in Health Journal / Revue de la Diversité de la Recherche en Santé Vol 4, January/ Janvier 2020 - ISSN: 2561 -1666 DOI : 10.28984/drhj.v4i1.337

In the second part of the study, the active distraction group was able to maintain the left leg extension for the longest period of time. Score means showed a difference between $35 \%$ to $43 \%$ longer than the passive distraction and control respectively. The active distraction group also perceived the least amount of physical exertion as was found by Gill and Strom (1985) in the use of a collage. Participants in their study could endure the leg extension longer than the "personal thought" internal distraction group and control group. The listening of music as a passive distraction did not improve performance nor did it significantly change RPE as found by Boutcher and Trenske's (1990). Despite participants having a choice of background music tempo, there was no effect on endurance time performance. This observation corroborates the findings of Szabo, Balogh, Gaspar, Bosze and Vaczi (2009).

The results in the third part of the study were not expected. The dominant grip endurance test revealed no significant differences. The duration of the task was relatively short for all groups. Perhaps a threshold of $40 \%$ was too high and consequently, the distraction time was insufficient as per Pennebaker's (1982) hypothesis of internal and external stimuli. A second reason for not having significant results may have been due to the type of exercise involved. Pandolf, Kamon and Noble (1978) found differences between eccentric and concentric exercises. It may be that a concentric exercise like the grip dynamometer was not suitable for examining smaller muscle endurance in this study.

This study found mixed results in the three trials. Trials one and two clearly showed, as expected that the active distraction group was least accurate in estimating the length of time they performed as they did reverse serial counting. It was anticipated that this distraction would lessen the discomfort and perceived fatigue during the leg raise and consequently increase the timed leg raise as per the competition for cues hypothesis.

The second trial of the study showed a much longer performance score for the active distraction group, suggesting that ignoring the leg extension task results in a better performance. It is unclear why similar results were not found for the right leg extension even though there is general leg endurance symmetry (Parkin, Nowicky, Rutherford \& McGregor, 2001, Turunen, H., Tenhonen, Sen \& Hanninen, 1996).

The active distraction group in the second study had the lowest statistical rating of perceived exertion. Heart rate did not change despite studies having shown high correlations with RPE and heart rate are (Borg, 1982; Garcin, M., Wolff, M. \& Bejma, T., 2003). These altered responses can be explained by Pandolf, Kamon and Noble's (1978) findings where differences were found in perceived effort between eccentric and concentric exercises at the same heart rate. Hampson, Gibson, Lambert and Noakes, (2001), in their review article, cite other correlation anomalies as seen with the use of biofeedback, hypnosis, pharmaceuticals and hot environments.

A possible explanation for having a change in ratings of perceived exertion in left leg study but not in the right leg study is the duration of the exercise. A $46 \%$ increase in performance time was recorded for the left leg. The longer performance time may have contributed to a more accurate rating of perceived exertion. Since trial 2 used the left leg after being tested on the right leg in trial 1, there may have been a learning effect. However, each participant would only have 
Diversity of Research in Health Journal / Revue de la Diversité de la Recherche en Santé

Vol 4, January/ Janvier 2020 - ISSN: 2561 -1666 DOI : 10.28984/drhj.v4i1.337

done a trial using a different intervention (music or reverse serial counting). Further research in this possibility should be considered.

The perceived fatigue questionnaire as outlined by Pennebaker and Lightner, (1980), did not show significant results between groups and between trials. Marked changes were not found by Couture, Jerome and Tihanyi, (1999) when participants swam for 10 to 12 minutes and by Couture et al. (1994) when participants marched for 3 hours. Pennebaker (1982) believes that fatigue relates to a consistent model where fatigue may result from either too much or too little stimulation. The results suggest that internal and external stimuli were not sufficiently different to be identified on the self-report questionnaire devised by Pennebaker and Skelton, (1978). It may be that the questionnaire was not adequate for this study.

In future studies, the single-item Visual Analogue Scale (VAS) could be considered as a possible replacement to the Perceived Fatigue Questionnaire (de Boer et al. 2004). The VAS assesses the global quality of life where the participant selects on a range from 0 to 100 the quality of life and it is deemed to be an instrument with a solid validity and reliability.

\section{Conclusion}

In summary, results do appear to support the "competition for cues" hypothesis to a certain extent. Though it is unclear if the control group used a distraction strategy on their own, the concept of limited capacity for information processing was evident in the second part of the study. Pennebaker (1982) suggests that quantity and quality of stimuli must be considered to optimally reduce the conscious thought of fatigue. Support through these findings suggest that duration and intensity (active vs. passive) must be further re-examined in future studies. With the exception of one trial, the active distraction group did not support a significantly lower rating of perceived exertion score and better performance.

\section{Acknowledgement}

I would like to acknowledge Kristin Bradley's important contribution to several phases of data collection in this study.

\section{References}

Baker, J., Côté, J., \& Deakin, J. (2005). Cognitive characteristics of expert, middle of the pack, and back of the pack ultra-endurance triathletes. Psychology of Sport and Exercise, 6(5), 551558. doi.org/10.1016/j.psychsport.2004.04.005.

Brick, N. E., Campbell, M. J., Sheehan, R. B., Fitzpatrick, B. L., \& MacIntyre, T. E. (2020). Metacognitive processes and attentional focus in recreational endurance runners. International Journal of Sport Exercise Psychology, 18(3), 362-379.

Borg, G. (1982). Psychophysical bases of perceived exertion. Medicine and Science in Sports and Exercise, 14, 337-381. 
Diversity of Research in Health Journal / Revue de la Diversité de la Recherche en Santé

Vol 4, January/ Janvier 2020 - ISSN: 2561 -1666 DOI : 10.28984/drhj.v4i1.337

Boutcher, Stephen H. and Trenske, Michelle (1990). The effects of sensory deprivation and music on perceived exertion and affect during exercise. Journal of Sport \& Exercise Psychology, 12(2), pp. 167-176.

Boya, M., Foulsham, T., Hettinga, F., Parry, D., Williams, E., Jones, H., ... (2017). Information acquisition differences between experienced and novice time trial cyclists. Medicine and Science in Sport and Exercise, 49, 1884-1898.

Carneiro, M. A. S., de Oliveira, A. A., Martins, F. M., Souza, A. P., Nunes, P. R. P., \& Orsatti, F. L. (2018). High-intensity interval body weight training promotes different adaptations to combined training in body composition and muscle strength in young women. Science \& Sports, 33(3), e105-e113.

Chen, D. \& Singer, R.N. (1992). Self-Regulation and Cognitive Strategies in Sport Participation. International Journal of Sport Psychology, 23, 277-300.

Couture, R.T., Tihanyi, J. \& St-Aubin, M. (1998). Can performance in a distance swim be improved by increasing a preferred cognitive thinking strategy? The Sport Journal, Summer [On-line serial], 1(1), , pp.1-6; http://www.thesportjournal.org.

Couture, R.T., Jerome, W. \& Tihanyi, J. (1999) Can Associative and Dissociative Strategies Affect the Swimming Performance in Recreational Swimmers? The Sport Psychologist, 13 (Sept), 334-343.

Couture, R.T., Singh, M., Lee, W., Chahal, P., Wankel, L., Oseen, M., ... (2000). Can Mental Training Help Police Improve Shooting Performance? Policing; An International Journal of Police Strategies \& Management, 22(4), 696-711.

de Boer AG, van Lanschot JJ, Stalmeier PF, van Sandick JW, Hulscher JB, de Haes JC, Sprangers MA. (2004). Is a single-item visual analogue scale as valid, reliable and responsive as multi-item scales in measuring quality of life? Quality Life Research, Mar;13(2):311-20. doi: 10.1023/B:QURE.0000018499.64574.1f. PMID: 15085903.

Eston, R. (2012). Use of ratings of perceived exertion in sports. International Journal of Sport Physiology and Performance, 7, 175-182.

Garcia-Lopez, D., de Paz, J.A., Moneo, E., Jimemez-Jimenez, R., Bresciani, G. \& Izqioerdo, M.I. (2007). Effects of short vs. long rest period between sets on elbow-flexor muscular endurance during resistance training to failure. Journal of Strength Conditioning Research, ;21(4):1320-4. doi: 10.1519/R-21096.1. PMID: 18076247.

Garcin, M., Wolff, M. \& Bejma, T. (2003) Reliability of rating scales of perceived exertion and heart rate during progressive and maximal constant load exercises till exhaustion in physical education students. International Journal of Sports Medicine, 24(4) 285-290.

Filligim, R. B., Roth, D. L. \& Haley, W. E. 1989. The effects of distraction on the perception of exercise-induced symptoms. Journal of Psychosomatic Research, 33(2), 241-248.

Finkelman, J. M. (1994). A large database study of the factors associated with work-induced fatigue. Human Factors, 36, 232-243.

Franklin, B. (1978). Motivating and educating adults to exercise. Journal of Physical Education and Recreation, 49(6), 13-17. 
Diversity of Research in Health Journal / Revue de la Diversité de la Recherche en Santé

Vol 4, January/ Janvier 2020 - ISSN: 2561 -1666 DOI : 10.28984/drhj.v4i1.337

Franklin, B. (1988). Program factors that influence exercise adherence: Practical adherence skill for the clinical staff. In R. Dishman, (Ed) Exercise adherence, its impact on public health, (pp. 237-258). Champaign, Illinois: Human Kinetics.

Gill, D.L. \& Stom, E.H. (1985). The effect of attentional focus on performance of an endurance Task. International Journal of Sport Psychology, 16, 217-223.

Hampson, D. B, Gibson, A., Lambert, M. I. \& Noakes, T. D. (2001). The influence of sensory cues on the perception of exertion during exercise and central regulation of exercise performance. Sports Medicine, 31(13), 935-953.

Hull, G. R. and Potteiger, J. A. (1999). Regulation of exercise intensity using ratings of perceived exertion during passive visual distraction. Perceptual \& Motor Skills, 89(2), 684-694.

Kravitz, L. (2009). Progression models in resistance training for healthy adults. IDEA Fitness Journal, 6(6), 19-22.

McCaul, K. D., \& Malott, J. M. (1984). Distraction and coping with pain. Psychological Bulletin, 95(3), 516-533. https://doi.org/10.1037/0033-2909.95.3.516

Martin, J. E., Dubbert, P. M., Katell, A. D., Thompson, J. K., Raczynski, J. R., Lake, M., ... Cohen, R. E. (1984). Behavioral control of exercise in sedentary adults: Studies 1 through 6. Journal of Consulting and Clinical Psychology, 52, 795-811

Masters, K.S. (1992). Hypnotic susceptibility, cognitive dissociation, and runner's high in a sample of marathon runners. American Journal of Clinical Hypnosis, 34(3), 193-201.

Padgett, V.R. \& Hill, A.K. (1989). Maximizing athletic performance in endurance events: A comparison of cognitive strategies. Journal of Applied Social Psychology, 19(4), 331-340.

Pandolf, K. B., Kamon, E. \& Noble, B. J. (1978). Perceived exertion and physiological responses during negative and positive work in climbing a ladder mill. Journal of Sports Medicine \& Physical Fitness, 18(3), 227-236.

Parkin, S., Nowicky, A.V., Rutherford, O.M., McGregor, A.H. (2001). Do oarsmen have asymmetries in the strength of their back and leg muscles? Journal of sports sciences, 19(7), 521-526.

Pennebaker, J.A. (1982). The Psychology of Physical Symptoms, New York; Springer-Verlag.

Pennebaker, J.A. \& Lightner, J.M. (1980). Competition of internal and external information in an exercise setting. Journal of Personality and Social Psychology, 39, 165-174.

Pennebaker, J.A. \& Skelton, J. (1978). Psychological parameters of physical symptoms. Personality and Social Psychology Bulletin. 4, 524-530.

Pensgaard, A.M. (1998). Stress, control, and coping in elite athletes. Scandinavian journal of medicine \& science in sports. 8(3), 183-189

Privitera, G. J., Antonelli, D. E., \& Szal, A. L. (2014). An enjoyable distraction during exercise augments the positive effects of exercise on mood. Journal of Sports Science \& Medicine. 13(2), 266-270.

Rejeski, J.W. \& Kenny, E. (1987). Distracting attentional focus from fatigue: Does task complexity make a difference? Journal of Sport Psychology, 9(3), 66-73. 
Diversity of Research in Health Journal / Revue de la Diversité de la Recherche en Santé

Vol 4, January/ Janvier 2020 - ISSN: 2561 -1666 DOI : 10.28984/drhj.v4i1.337

Schuker, L., Hagemaan, N., Strauss B. \& Volker, K. (2009). The effect of attentional focus on running economy. Journal of Sports Sciences. 27, 1241-1248.

Senna, G. W., Rodrigues, B. M., Sandy, D., Scudese, E., Bianco, A., \& Dantas, E. H. M. (2017). Heavy vs light load single-joint exercise performance with different rest intervals. Journal of Human Kinetics. 58(1), 197-206.

Stevinson, C. D. \& Biddle, S.J. (1998) Cognitive orientations in marathon running and "hitting the wall". British Journal of Sports Medicine.32:229-234.

Szabo, A., Balogh, L., Gaspar, Z., Bosze, J. \& Vaczi, M. (2009). The effects of fast and slow tempo music on recreational basketball training. International Quarterly of Sport Science, 2, 1-13.

Turunen, H., Tenhonen, S., Sen, C.K. \& Hanninen, O. (1996). Activation symmetry of right and left femoris muscles in untrained students, soccer players and elite runners. Coaching and Sport Science Journal, 1(4), 20-24.

Waugh, C. E., Shing, E. Z., \& Furr, R. M. (2020). Not all disengagement coping strategies are created equal: positive distraction, but not avoidance, can be an adaptive coping strategy for chronic life stressors. Anxiety, Stress \& Coping, 33(5), 511-529.

Weinberg, R. \& Gould, D. (1995). Foundations of Sport and Exercise Psychology, Champaign, Illinois: Human Kinetics. 